\title{
HYDRAULIC RISK ASSESSMENT IN ARCHAEOLOGICAL SITES SUPPORTED BY AN INTEGRATED DIGITAL SURVEY - CFD (COMPUTATIONAL FLUID DYNAMICS) MONITORING APPROACH
}

\author{
G. D’Agostino ${ }^{1}$, M. Figuera ${ }^{2}$, V. Pennisi ${ }^{1}$, G. Russo ${ }^{1}$, M. Sanfilippo ${ }^{1}$, P.M. Militello², R.E. Musumeci ${ }^{1}$ \\ ${ }^{1}$ Department of Civil Engineering and Architecture, University of Catania, Via Santa Sofia n. 64 95123, Catania, Italy \\ (graziana.dagostino, valeria.pennisi, mariano.sanfilippo, rosaria.musumeci)@unict.it, gloria.russo@studium.unict.it \\ ${ }^{2}$ Department of Human Science, University of Catania, Piazza Dante n. 24 95124, Catania, Italy \\ (marianna.figuera, milipi)@unict.it
} KEY WORDS: rock-cut architecture, hypogeum, digital survey, 3D reconstruction, archaeological site, flood risk, hydraulic analyses,
water infiltration.

\begin{abstract}
:
This paper presents a methodological approach for analysing and evaluating hydraulic risks in complex archaeological areas, and thereby substantially improve general preservation and conservation efforts involving cultural heritage.

The hypogeum of Calaforno (province of Ragusa, Sicily) represents a unique sample of rock-cut architecture in terms of size and architectural features, and an ideal candidate for the case study due to its high historical, archaeological and cultural significance, as well as its intrinsic fragility and criticality associated with hydrogeological and seismic factors.

The interdisciplinary research approach involved archaeological and engineering contributions towards the development of numerical models for the assessment of hydraulic risks threatening archaeological heritage. The morphological characteristics of the site rendered the use of a Laser Scanner necessary for three-dimensional survey.

The prehistoric structures currently undergoing excavation outside the main entrance of the monument have raised concerns regarding the impact of the Manna stream, which flows a few meters from the main entrance to the hypogeum, which has seen periodic flooding in some of its rooms. Simulations of these flooding events were performed in order to attain better understanding of the hydraulic phenomena influencing the site, especially regarding the dynamics associated with surface runoff.

The interdisciplinary approach to this research, combining in-depth archaeological expertise with digital 3D surveying and modelling technologies, has proven fundamental to the effective monitoring of this morphologically complex site, and should perhaps be considered integral to any preventive assessment and risk management initiative involving cultural heritage.
\end{abstract}

\section{INTRODUCTION}

The work herein is based on themes surrounding the analysis and evaluation of hydraulic risks in complex archaeological areas in order to accompany and assist general preservation and conservation efforts regarding cultural heritage. The hypogeum of Calaforno, in the province of Ragusa (Fig. 1), is an outstanding specimen of Sicilian prehistorical architecture. Whereas rock-cut funerary chambers dating as far back as the late Neolithic period are relatively common in Sicily, no known example offers the number of rooms and complexity of Calaforno, inspired perhaps by certain peculiar local traditions.

Modern studies of the hypogeum began with a long article by L. Guzzardi in the 1970's, but it was not until 2013 that the Department of Humanities of the University of Catania was invited by Dr. Giovanni Di Stefano, director of the Archaeological Park of Camarina, to resume investigation of the site, under my direction (1). Afterwards, the Superintendence BB.CC.AA. of Ragusa undertook soundings outside the hypogeum for touristic enhancement.

\footnotetext{
(1) Excavations conducted in 2013 and 2017; architectural study of site and material in 2014-15 and 2018. We wish to thank the Superintendence BB.CC.AA. of Ragusa and the Calaforno Forest Park for permission to undertake our research, especially Giovanni di Stefano, Rosalba Panvini, Calogero Rizzuto, Antonino De Marco, and Tullio Serges. Considerable help was generously provided by colleagues of the Superintendence, Anna Maria Sammito and Saverio Scerra.
}

Since then, our attention has evolved from purely scientific interest to a broader perspective of public archaeology, due also to the enthusiastic participation of the Giarratana and Monterosso Almo local communities (2): a digital survey and 3D reconstruction of the hypogeum was performed to obtain an accurate and updated graphic documentation and to develop the beginnings of an immersive virtual experience simulating an actual tour of the hypogeum based on recent surveys by the Superintendence. Significant preservation issues, however, soon surfaced in the form of violent flooding during 2017-18 (repeated almost certainly throughout the history of the site), representing a significant threat to the monument and a hindrance to its fruition. On the basis of these findings, Calaforno was qualified as a test site for the Early Warning Alarm System (eWAS) project (3), with the aim of analysing natural threats and countermechanisms through intensive collaboration between archaeologists of the Department of Human Sciences and engineers of the Department of Civil Engineering and Architecture (University of Catania). The site has been chosen specifically for its high historical, archaeological and cultural

\footnotetext{
(2) Special thanks to the head of the council of Giarratana, Dr. Bartolo Giaquinta, for his invaluable help in managing practical aspects of the archaeological mission. (3) "eWAS - early Warning Alarm System - Un sistema di allerta precoce per il patrimonio culturale". Progetto PON ARS01_00926.
} 
significance, as well as for its intrinsic fragility and criticality associated with hydrogeological and seismic factors. This article presents the preliminary results of this multidisciplinary collaboration.

P. M. Militello
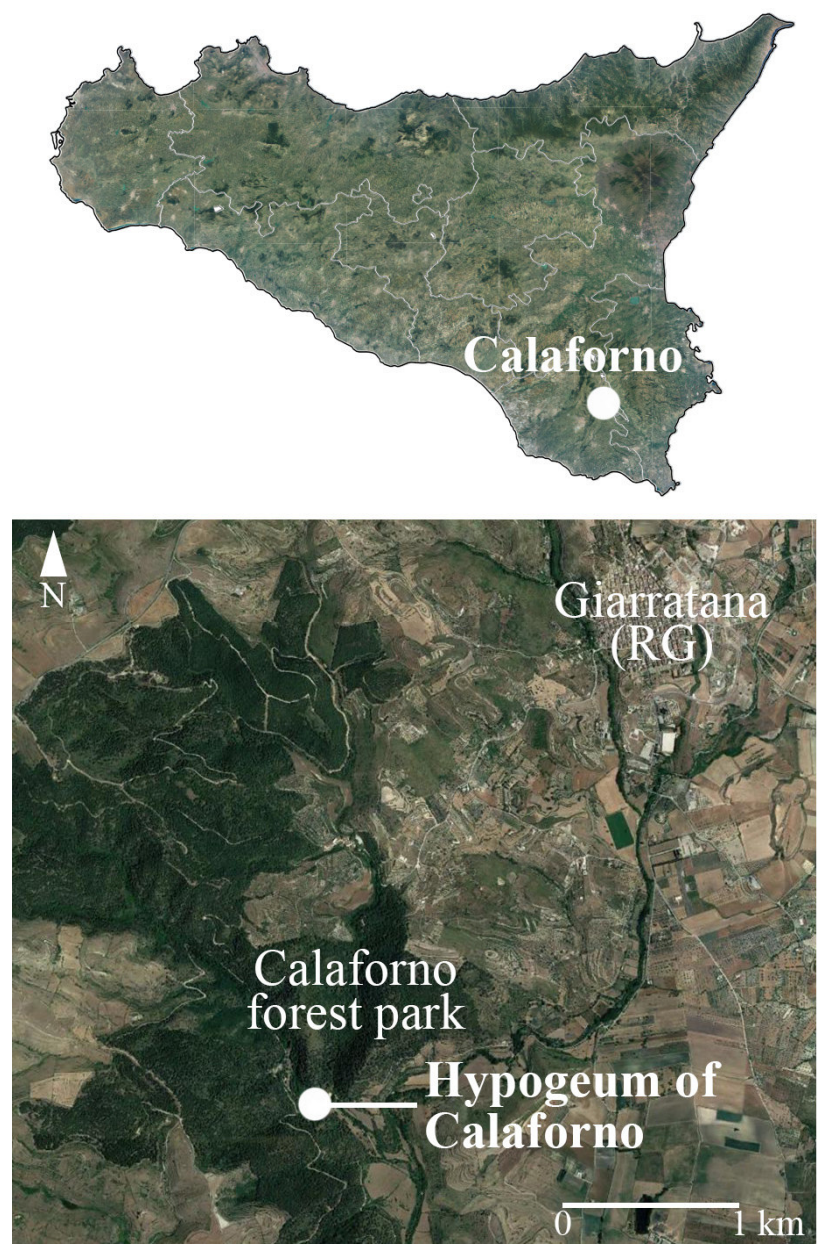

Figure 1. The hypogeum of Calaforno geolocalization.

\section{RELATED WORKS}

As underlined by UNESCO (2010), our heritage is increasingly affected by natural phenomena, even those not considered in the global register of catastrophic risks. Recent studies have furthermore highlighted the relationship between natural hazards and the little remaining or permanently lost cultural heritage (Dassanayake et al., 2012; Murthy, 2013; Nicu, 2019).

Hydrological and hydraulic risks such as floods, debris flows, humidity and erosion are widely recognized for their catastrophic potential, and several studies have attempted to assess the hydraulic risks in historical cities, including the impact of climate change (Lanza, 2003; European Parliament, 2007; Arrighi et al., 2013; Camuffo et al., 2014; Arrighi et al., 2018). Recently, Musumeci et al. (2021) applied historical analyses, field surveys, geomorphological and hydrological investigations, and twodimensional hydraulic numerical models in order to assess the hydraulic risks and devise an early warning and reporting system for the UNESCO Roman Villa del Casale (Italy).

The current research on the Calaforno site aims also to create a polygonal model using a point cloud generated from laser scanning of the area; the 3D model will then be used to analyse the hydrogeological criticalities of the site. The characteristics of the site will also allow suitable experimentation of different digital survey techniques aimed at the comprehensive documentation and virtual fruition of similar heritage assets.

In recent years, several research groups have investigated the application of digital surveys to underground archaeological sites (Ebolese et al., 2019; Alessandri et al., 2020; Perfetti et al., 2018; Saulli et al., 2018), aimed at developing digital graphic and volumetric representations of the morphological complexity of the surfaces. The studies revealed how the lack of illumination, the presence of narrow spaces, difficult accessibility, irregular morphologies and the presence of water and humidity are highly significant factors for determining surveying strategies around quarries, caves and underground environments.

In an interesting study involving the Bat Cave of the Pantalica Nature Reserve (RG), the digital replication of the cave was obtained through the integration of laser scanning and photogrammetric survey techniques (Aiello et al., 2019a). This allowed the generation of an immersive virtual fruition experience in alternative to a real tour, thereby limiting anthropic pressure around the dwellings of the bat colony. Both in this study and the Domica Cave study in Slovakia (Gallay et al., 2015), lighting conditions and site morphology heavily influenced the in situ survey activities. In the second case, laser scanning allowed three-dimensional acquisition of some of the more difficult areas to access. The 3D model obtained allowed the analysis of the volumetric properties and morphology of the cave, and was subsequently georeferenced and inserted in a GIS platform for the study of the entire karst landscape and related phenomena.

Research on the Catacombs of San Giovanni (SR) addressed metric acquisition difficulties related to narrow spaces and lack of illumination (Bonacini et al., 2013; Santagati, 2014). The laser scanning survey allowed the geometric and spatial representation of the underground environments, rectifying some of the inaccuracies in pre-existing graphic documentation. The integration of laser scanning and photogrammetric survey methodologies is particularly useful for the acquisition of chromatic data involving underground environments with poor lighting. Examples of this are the survey of the hypogeum of Crispia Salvia in Marsala (TP) (Tanasi et al., 2021) and the survey of the Palazzo Campana caves in Osimo (AN) (Clini et al., 2019), which have frescoes and bas-reliefs inside them.

As shown by the research conducted on the underground passages in the First World War fortifications in the Trentino region (Rodríguez-Gonzálvez et al., 2015) and on the Ochtiná Aragonite Cave in Slovakia (Pukanská et al., 2020), a clear understanding of the purposes of three-dimensional reconstruction is integral to choosing the most appropriate digital survey technique among two-dimensional documentation, virtual fruition, hydrogeological analysis, static and dynamic analysis, etc.

Drawing on these related studies, this paper aims to assess the risks facing the Calaforno hypogeum site with respect to the presence of water.

V. Pennisi, G. Russo

\section{METHODOLOGY}

Intrinsically valuable and important archaeological sites warrant maximum possible enhancement efforts and environmental risk assessments, including hydraulic risk evaluation.

The proposed methodological approach to the analysis and the evaluation of hydrogeological risk in such a complex archaeological area is based on an interdisciplinary approach involving archaeological and engineering disciplines, including many methodological stages. In particular, the chosen methodology includes preliminary archaeological analysis, 
digital survey and 3D modelling, as well as hydrological and geomorphological analysis. As shown in Figure 2, these analyses aim to determine the extent of flooding around and inside the archaeological area and to discover the underlying motivation for the presence of huge stones inside the hypogeum.

The methodological proposal covers the following stages:

1) archaeological investigation of the site;

2) 3D data acquisition from previous digital survey phases (2017-

19) and integration of current 3D data (2020-21);

3) selection of the appropriate level of detail of the polygonal model of the hypogeum obtained from the point cloud;

4) hydraulic and geomorphological analysis of the drainage basin in which the site is located;

5) a $2 \mathrm{D}$ numerical simulation of the extent of flooding events in the basin;

6) analytical analyses of the transport of solids into the hypogeum.

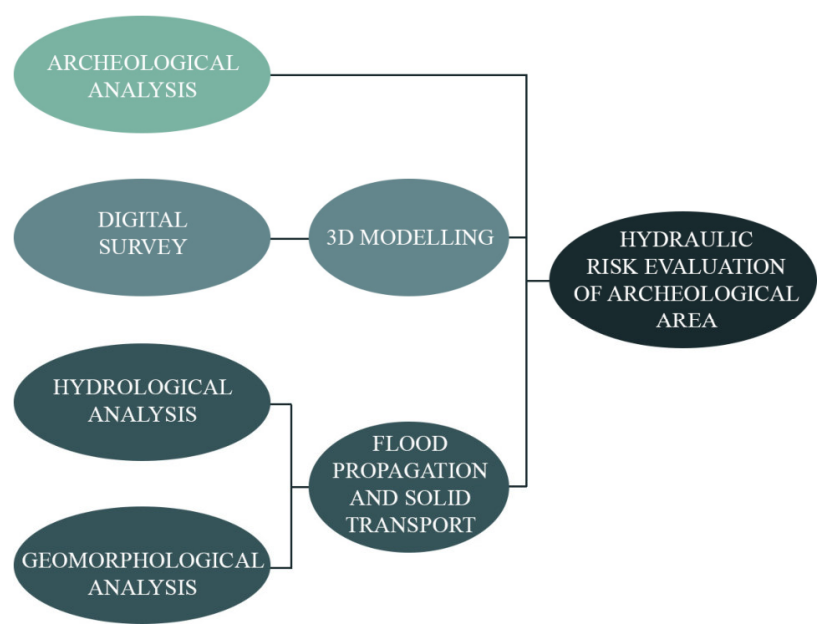

Figure 2. Methodological pipeline.

An archaeological analysis was initially performed to determine the historical use of the area and the reasons for its current geomorphological shape. This analysis concerns the investigations undertaken to reconstruct the chronology of the construction and its use phases through architectural analysis of the monument and study of its morphological features, in addition to clarifying its functional aspects. The characteristics of its architecture and the necessity for more comprehensive results have led to a less conventional surveying and analytical method for this monument in order to circumvent the many scientific issues that compromised the first survey (Guzzardi, 1980), as well as to identify previously undiscovered architectural elements and to record the current state of preservation in enough detail to be able to adequately monitor any future degradation.

A digital survey was employed to create a true polygonal model and to validate or update existing graphical documentation. The use of a laser scanner allowed the generation of a very accurate point cloud, and the numerical model was geo-referenced to verify the actual position and orientation of the hypogeum with respect to the catchment area and the main internal slopes. The entire process culminated in the generation of a faithful polygonal model on which subsequent three-dimensional hydrogeological analysis could be based.

Geomorphological, hydraulic and hydrological analyses of drainage catchment area around the hypogeum was conducted. The geomorphological analysis was employed to define the drainage basin and its outlet downstream of the site, and provide accurate information regarding soil composition and features. The hydraulic and hydrogeological analysis involved defining rainfall patterns from historical data and examining the ground flows through an inflow-outflow model.

2D numerical simulation was implemented to estimate the magnitude of extreme events that have impacted the hypogeum in the past, allowing simulation of flood propagations and peak runoff rates during extreme events. These values were used to model flood propagation at the site and to assess whether the forces involved could justify the presence of solids in the hypogeum, as well as the potential water damage.

G. D'Agostino, M. Figuera, V. Pennisi

\section{THE HYPOGEUM OF CALAFORNO}

The hypogeum of Calaforno (Fig. 3) was until a few years ago labelled a minor site due to its distance from popular tourist circuits, but various archaeological evidence suggests a much higher archaeological significance of its surroundings, especially with respect to the prehistorical era that witnessed a large concentration of hypogeum structures, rock-cut tombs and other complex structures (Figuera, 2018). The monumental hypogeum was identified in the 1970s by Lorenzo Guzzardi (1980) and, notwithstanding the special characteristics that render it one of the most important prehistoric monuments in Sicily, the hypogeum did not undergo systematic investigation until 2013, which saw a veritable increase in excavation and surveying activities. Through the work led by the University of Catania, under the direction of Pietro Militello (Militello and Di Stefano, 2015; Militello, 2021) and the Superintendence BB.CC.AA. of Ragusa (Militello et al., 2018), the hypogeum was rediscovered with new interpretations of the monument and its surrounding landscape.

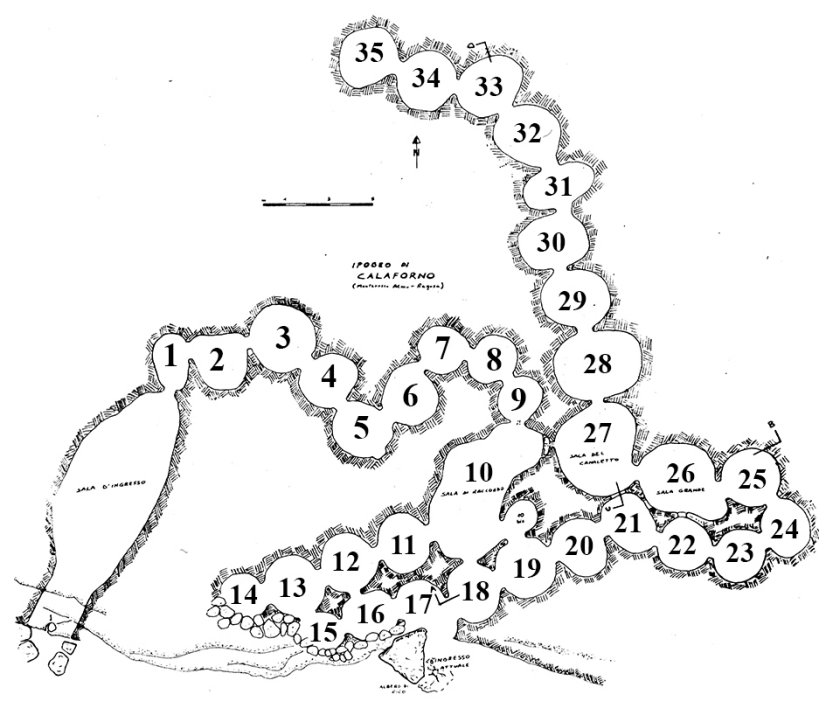

Figure 3. The hypogeum of Calaforno (first survey by Guzzardi 1980).

\subsection{Chronological and functional issues}

The construction of the hypogeum spanned from the Late Copper Age (ca. 2700-2200 BC) to the Early and Middle Bronze Age (ca. $2200-1250 \mathrm{BC})$. The planimetry suggests that the first section nearest the main entrance was the earliest, while the technologically more advanced second section was added perhaps later. It had different uses interspersed with periods of abandonment. It was initially used as a burial site until it became a ritual area in honour of the ancestors between 1000 and $700 \mathrm{BC}$. After a period of abandonment (excluding the immediate external 
area, which continued to be frequented) during the Greek period, it was partially reoccupied as a cemetery (ca. 300-500 AD), and as an industrial and stockage area or an animal shelter (ca. 800$1050 \mathrm{AD}$ ) until the final collapse of the entrance.

\subsection{Morphological features}

The hypogeum is carved into a layer of soft marl lying beneath a harder limestone layer. From the technological perspective the excavation was facilitated by geomorphologic features and the presence of these sub-horizontal layers: the rooms were dug in the soft layer, with concave floors and walls slightly curving towards the perfectly flat ceiling formed by the harder rock.

The hypogeum consists of a wide entrance and 35 circular rooms forming an irregular route approximately $100 \mathrm{~m}$ long. A monumental entrance excavated by the Superintendence (Militello et al., 2018) consisted of many large blocks and a complex dromos structure. The first room is wide (ca. $12 \times 4 \mathrm{~m}$ ), the following 35 rooms have a diameter ranging from 1.5 to $3 \mathrm{~m}$, and range in height from 1.6 to $1.8 \mathrm{~m}$. The construction ability of the builders is undeniable, and it is possible to distinguish sections with different design concepts. The smaller and lower rooms 1-9 are arranged along a serpentine route up to the first large connecting room 10 . The ability to preserve alignments and avoid interference between the different units is clear in the highest groups of rooms 11-14, 15-21, and 28-30, perfectly organized in three axial groups connected by rooms $22-25$ arranged in a ring shape. In this sequence, the connecting rooms 26-27 stand out because of their dimensions. The last group of rooms, 27-35, are oriented differently and vary in size. When the original access was obstructed by a partial collapse, a second entrance was added in the vicinity of room 17.

Between the rooms, there are various openings reaching the ceiling and smaller openings whose original shape is difficult to discern, some of which evidently reworked or enlarged in subsequent phases (Fig. 4a, c, d). In the first phase, each opening was probably closed by door slabs typical of funerary contexts, but very few of these remain in the rooms today. It is evident that the vicissitudes witnessed by the hypogeum hinders interpretation of the distribution of these mobile lithic elements. It is therefore necessary to distinguish between in situ and non in situ elements: among the former, it is certainly possible to include the slabs that are still close to the entrances (e.g. room 2, Fig. 4b), while the greatest concentration found in the main entrance undoubtedly belongs to the second group.

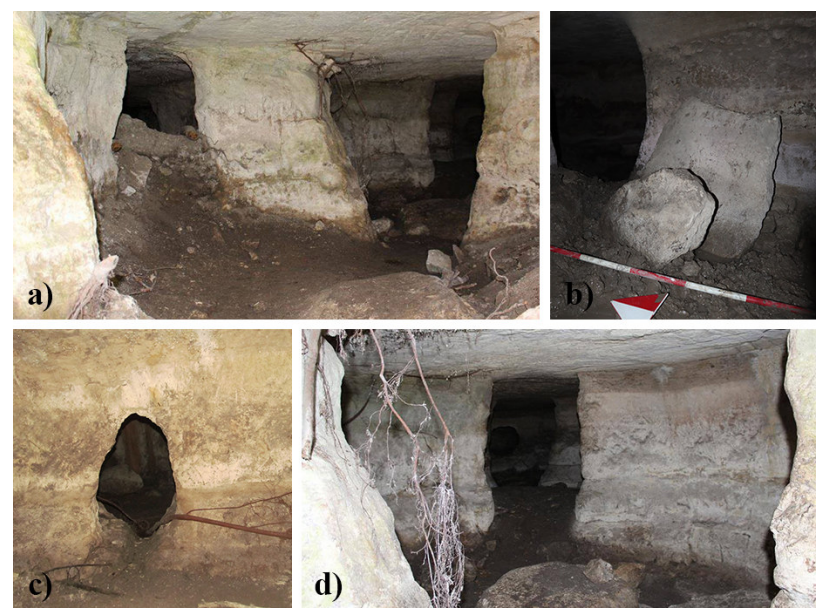

Figure 4. Architectural features: openings between the rooms and door slabs.
Here it is possible to distinguish two types of lithic elements with different morphological aspects: the slabs range in width between 9 and $18 \mathrm{~cm}$, while the blocks are larger in size (Fig. 5).

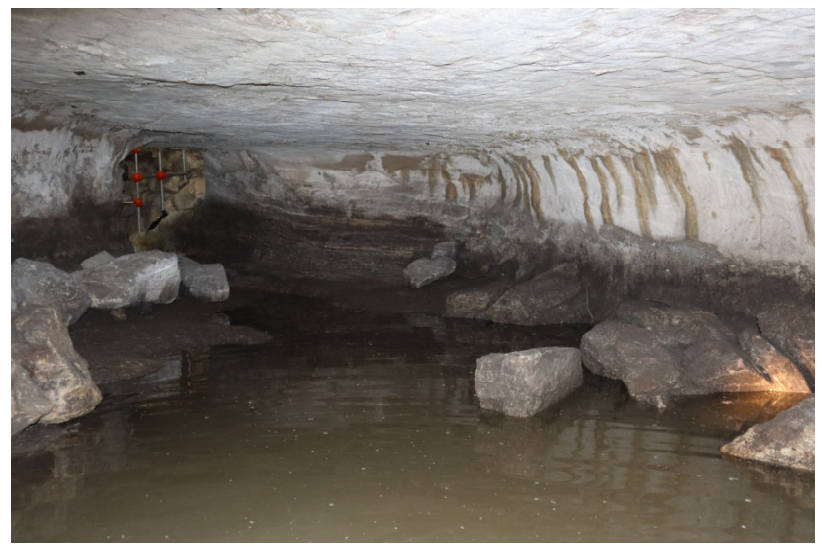

Figure 5. The main entrance with the greatest concentration of slabs and blocks.

The presence of door slabs can be explained as a voluntary accumulation over a phase in which the hypogeum no longer had a funerary function leaving the openings free, perhaps to facilitate other kinds of activities. While there is uncertainty surrounding the function of the blocks and whether they originated from the outside or are residues of the excavation left inside the hypogeum. The hydraulic analysis plays a fundamental role in this respect.

M. Figuera

\section{DIGITAL SURVEY AND 3D MODELLING}

The documentation, fruition and enhancement of an archaeological area should nowadays involve the integration of laser scanning and photogrammetric survey techniques and specific processes to manage the acquisition of less accessible, morphologically complex hypogeal environments that offer scant lighting. Current research on the hypogeum of Calaforno is following three different approaches: the first involves updating two-dimensional graphic documentation of the monument; the second entails high-resolution photorealistic polygonal modelling to allow virtual fruition of the rooms inside the hypogeum; the third leads to the creation of a digital replica tested at different levels of detail according to the different analyses. This paper mainly concerns the third approach, being the digital surveying and three-dimensional modelling aimed to facilitate the analysis and evaluation of hydrogeological risks in complex archaeological areas.

\subsection{Digital Survey}

The particular morphological and environmental characteristics of the site made it necessary to use a laser scanner for the metric acquisition. The digital survey started in 2017 and has been mainly dedicated to the three-dimensional acquisition of the more easily accessible rooms not subject to flooding. In 2017-19, the survey was conducted using a Leica P30 laser scanner to obtain a point cloud of approximately 250 million points. Considering the extension of the scanned area and the narrow dimensions of each room, the scanning resolution was set to $6.2 \mathrm{~mm}$ at $10 \mathrm{~m}$ in order to obtain an accurate numerical model and a wide area of overlap through the narrow passages. Due to the total lack of illumination, the internal camera of the laser scanner was unable to obtain RGB colour information of the indoor rooms. 
Between 2020 and 2021, the previous numerical model was integrated with the survey of the missing interior and exterior areas for the above mentioned reasons. The new survey project was based on the extension of the survey area towards the external environments, focusing on the presence of vegetation, various terrain elevations, and introduced elements such as the temporary roof that protects the access dromos to the main entrance. Drain pumps were also deployed for the flooded indoor rooms that had never been surveyed. This facilitated the 3D acquisition phases to obtain a comprehensive point cloud of the site using the Leica P30 and BLK360 laser scanners. The point clouds were aligned using the Cyclone Register 360 software by Leica Geosystem. Additionally, to reference the point cloud models, six geodetic ground control points were set around the open air scanned area and premeasured using the Leica GS18 GNSS-RTK (Fig. 6).
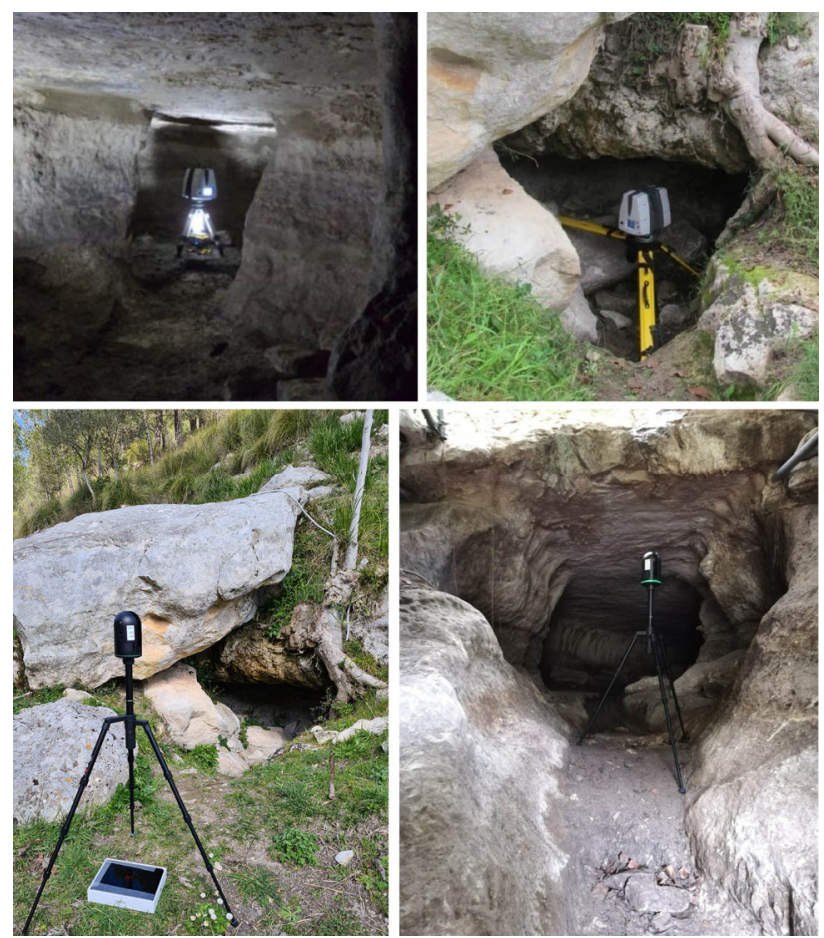

Figure 6. On site acquisition: top, 2017-19; down, 2021.

Thanks to the high resolution of the point cloud (about 600 million points), it is possible to obtain a digital copy and test the level of detail of the 3D model, which is critical for subsequent investigations. Currently, the research group is testing a workflow to obtain a model with high quality RGB colour information through the low cost survey technique: Structure from Motion survey with the wide-angle lenses of GoPro Action Cam (Aiello et al., 2019b; D'Agostino et al., 2021). The aims of the present study, however, are far more reliant on the creation of a geometrically realistic model than on tenable chromatic data. For this reason, the model RGB values have not been taken into consideration at this stage.

The workflow is based on data acquisition and 3D modelling carried out with attention to the monumental entrance consisting of a megalithic dromos and the wide main entrance room of the hypogeum (Fig. 7).

G. D'Agostino

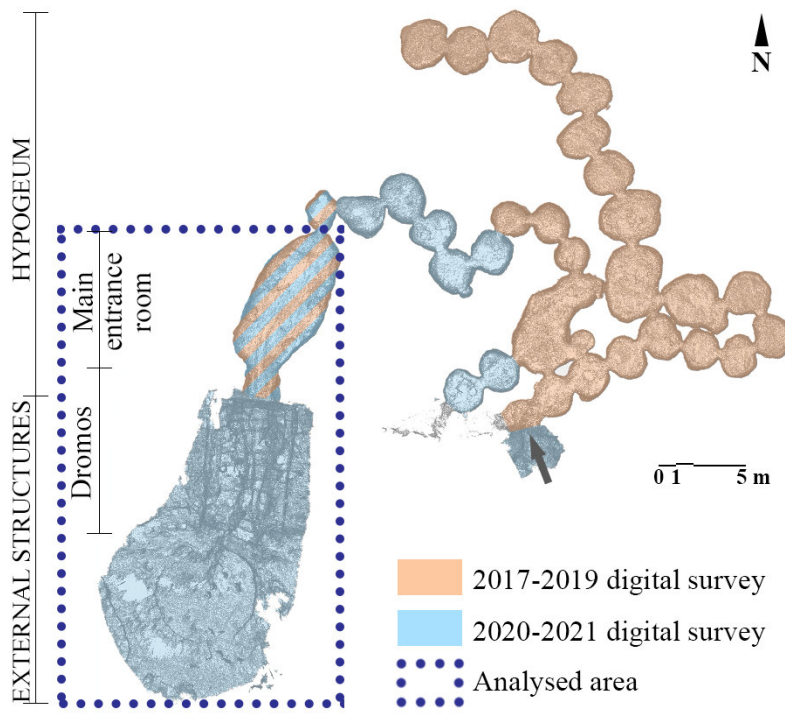

Figure 7. Top view of the final laser scanner point cloud.

\subsection{Post-processing and 3D modelling}

Before creating the polygonal model, the parts of the point cloud that were not needed for subsequent analysis were removed. The external vegetation and part of the ground, the temporary roof and the internal rooms of the hypogeum were removed, leaving only the access to the megalithic dromos and the main entrance room. Inside the dromos, there is a tubular element structure that the Superintendence inserted to secure the vertical walls. This represents a disturbing element for the three-dimensional model, and was carefully edited out of the model. Given the irregularity of the surfaces, a noise filter was applied to eliminate the sparse points with excessive deviations from the cloud with uniform density and reduce the cloud to approximately 900 thousand points.

This step and the subsequent mesh creation steps were carried out using Leica Geosystem 3D-Reshaper software. The creation of a complete and topologically correct 3D model can be conducted to different levels of detail according to research requirements and model optimization that can be duly processed by subsequent software. Two different levels of detail were tested, modifying the deviation error, maximum number of triangles, and minimum triangle size parameters (Fig. 8).
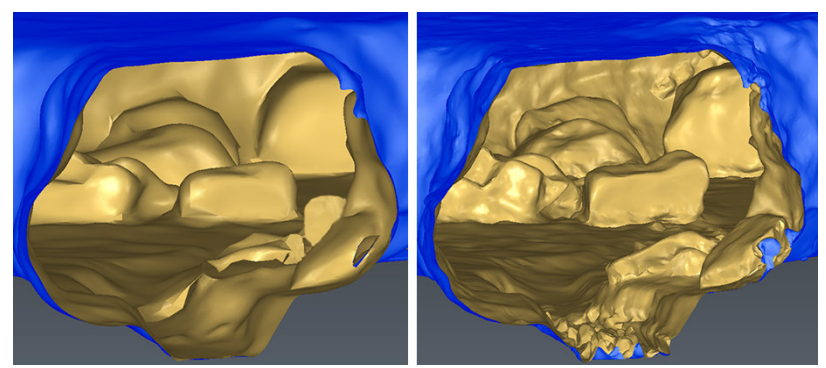

Figure 8. Comparison between the mesh obtained with different levels of detail.

As current research on the Calaforno site aims to create a detailed model for virtual use as well as a simplified model for in-depth hydraulic and geomorphological analysis, two models of the analysed portion of the hypogeum were produced with approximately 7 million and 1 million triangles, respectively. 
For the research aims presented here, digital survey and 3D modelling combined with fundamental archaeological research all contributed to the identification, positioning and dimensioning of the large blocks inside the main wide entrance room. Figure 9 shows the 16 blocks of uncertain function and origin.

G. D'Agostino, G. Russo

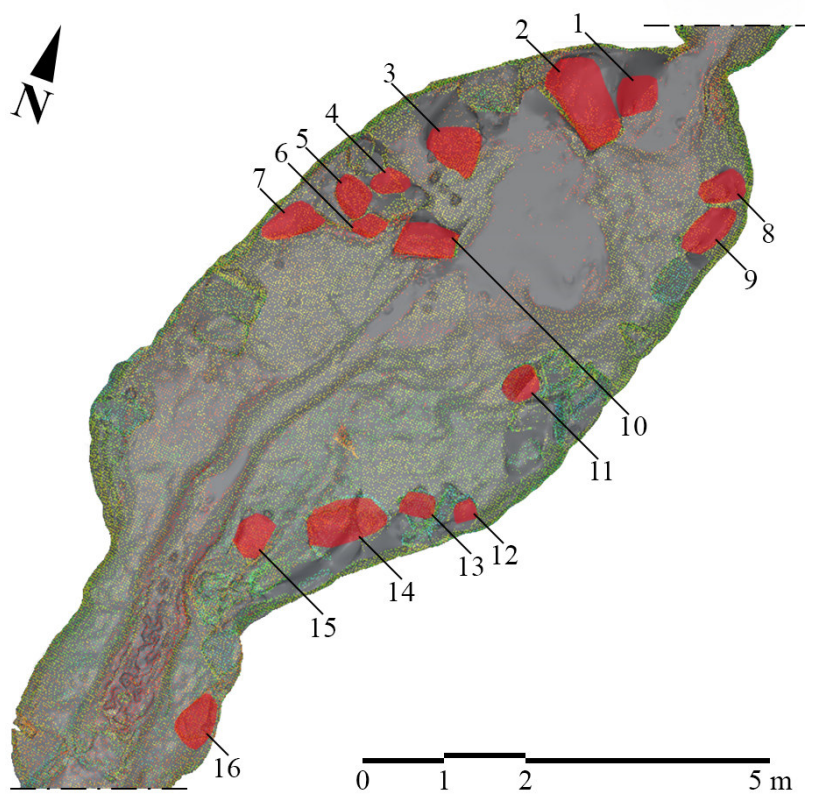

Figure 9. Top view of the interior main entrance room $3 \mathrm{D}$ model with the identification of the 16 blocks of uncertain function and origin.

\section{HYDRAULIC RISK ASSESSMENT}

This section analyses the hydrological vulnerability of the site associated with the response of the territory to intense rainfall. The events were studied at the basin scale, so a preliminary survey of the catchment area and a reconstruction of the most significant flooding events were carried out. The flood risk exposure analysis was performed by numerical modelling. These studies represent the starting point to identify the criticalities of the area, to determine flood propagation inside the hypogeum, and to establish protection measures for this heritage site.

\subsection{Catchment area and hydrological}

The delimitation of the basin was carried out with the DTM $2 \times 2 \mathrm{~m}$, provided by the Sicilian Region (2007). The SAGA-GIS software has been used to gain information on the catchment area of interest and on the drainage network, extracted from the DTM according to the conventional method proposed by O'Callaghan and Mark (1984). The hypogeum basin shown in Figure 10, with closing section located immediately downstream of the site, extends approximately $2.90 \mathrm{~km}^{2}$ with $367 \mathrm{~m}$ height variation between the maximum altitude of $808 \mathrm{~m}$ and the minimum of about $441 \mathrm{~m}$. The basin is characterized by several small tributaries flowing down from the slopes. The higher gradient values at the top, with local values often higher than $70 \%$, average to around $25 \%$ over the entire basin surface. The high slope bestows the surface runoff waters with high erosive potential. The main reach has an overall development of about
$3.5 \mathrm{~km}$ and an average gradient of $9 \%$. The basin concentration time is about 35 minutes.

The hydrological analysis of the basin is aimed at generating pluviometric probability curves, and given the return time of a rain event, it will be possible to estimate the relationship between rainfall height and duration. The study was carried out through the statistical analysis of rainfall data, with reference to the maximum rainfall intensity recorded at the Chiaramonte Gulfi pluviometric station, located near the hypogeum. The maximum annual rainfall data over 1, 3, 6, 12, 24 hours are available in the Annals of the Osservatorio delle Acque della Regione Sicilia, taken between 1974 and 2015. The Gumbel probability distribution, asymptotic of the maximum value, was adapted to each time series of data, verifying the goodness of fit of this function to the data set. It was possible to obtain the pluviometric probability curves for different return time values (Fig. 10).

a)

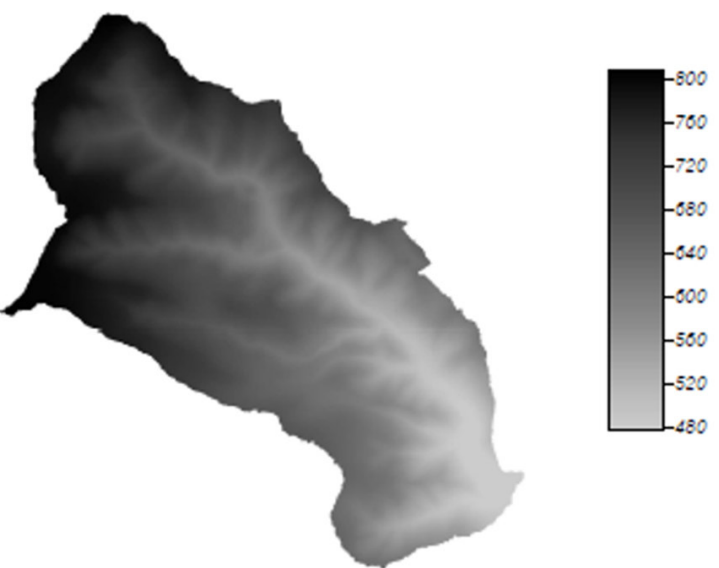

b)

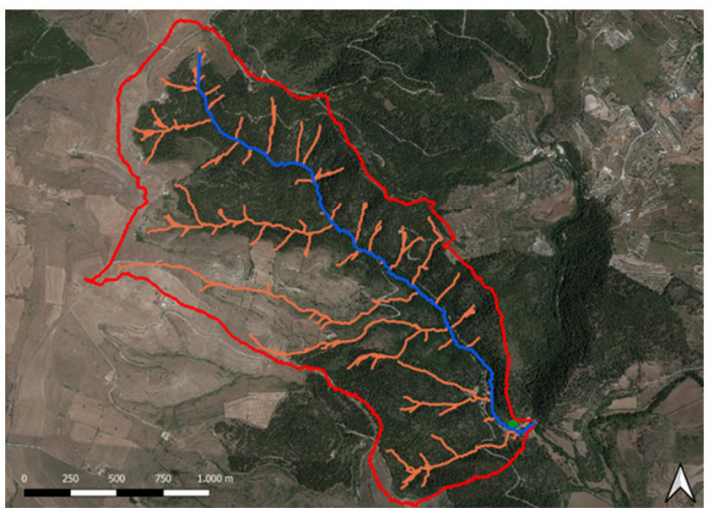

c)

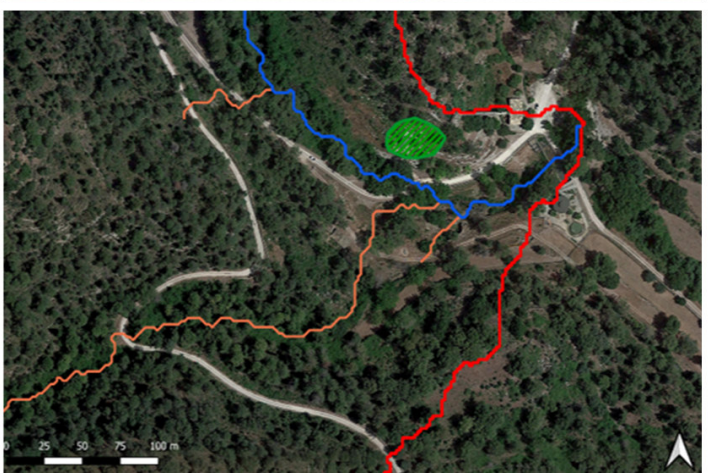

Figure 10. Catchment area of the Calaforno hypogeum. a) analysed DTM; b) overall view of the basin and c) location of the Calaforno hypogeum, within the basin close to the closing

section. In red the perimeter of the basin, in orange the hydrographic network, in blue the main shaft and in green the position of the hypogeum. 
Based on the geomorphological characteristics of the catchment and the relationship between rainfall height and duration of precipitation for the return time considered, it was possible to establish the value of the flood peak flow rate at the closing section using the rational or Turazza method. The report considers a critical rainfall duration equal to the basin concentration time. A runoff coefficient of 0.5 is set, in accordance with Frevert's table, since the regional technical map of land use reveals a dense presence of land suitable for agricultural crops, consisting mainly of olive groves. Table 1 reports the peak flow rate values calculated for the different flooding return period.

\begin{tabular}{|l|c|c|}
\hline Return time & $\mathrm{h}_{\operatorname{Tr}}(\mathrm{cc})$ & $\mathrm{Q}_{\mathrm{c}}$ \\
\hline & $\mathrm{mm}$ & $\mathrm{m}^{3} / \mathrm{s}$ \\
$\operatorname{Tr}$ 5 years & 35.17 & 21.84 \\
$\operatorname{Tr}$ 10 years & 41.27 & 25.62 \\
$\operatorname{Tr}$ 30 years & 50.48 & 31.34 \\
$\operatorname{Tr}$ 50 years & 54.67 & 33.94 \\
$\operatorname{Tr}$ 100 years & 60.33 & 37.45 \\
$\operatorname{Tr}$ 300 years & 69.25 & 42.99 \\
\hline
\end{tabular}

Table 1. Rainfall height calculated from the pluviometric probability curves for the considered return time and basin concentration time and peak flow rate according to the rational or Turazza method.

\subsection{Numerical simulation of flow propagation on the catchment area}

The commercial FLO-2D modelling software developed by J. S. O'Brien in 1986 is an internationally recognized tool, particularly effective at delimiting areas at risk of flooding and for the consequent design of mitigation works. It allows the simulation of the outflow of both liquid flows and solid transport carried by a consistent mass (solid transport, mud or debris flows). In particular, the model is a fixed bottom for simulations of debris flows and a movable bottom for simulations of ordinary transport.

The hydraulic model created for the numerical simulations is based on a square mesh calculation grid with a $10 \times 10 \mathrm{~m}$ side and georeferenced.

The most severe scenario referring to a meteorological event with a return time of 300 years is implemented within the FLO-2D numerical code in order to verify whether the archaeological area of the hypogeum of Calaforno may be affected by flood phenomena due to the runoff of rainwater. The result allows us to highlight the hydrogeological risks for the site and open up further research into the disappearance and interment of the site over the centuries.

The simulation has a total duration of 3 hours in order to achieve the peak flow rate at the closing section and then allow free water flow at the end of the event, considering a rectangular rain iethogram characterized by constant rain intensity during the simulation.

Furthermore, the presence of a road crossing was included in the simulation to constitute an obstacle to the free flow of rainwater. In fact, even if there is a conduit to redirect ordinary flows, the lack of maintenance and the presence of wood and other debris in the riverbed would probably obstruct this deviation during flood events.

The results of the numerical simulations shown in Figure 11 reveal that near area where the Calaforno hypogeum widens, the water rods rise up to $2.5 \mathrm{~m}$, also due to the presence of the outflow barrier represented by the road crossing. This phenomenon creates an upstream water level increase, with the risk of reaching the entrance to the hypogeum and flooding the internal areas. The results on the maximum flow rates shown in Figure 12 reveal peaks of over $2.5 \mathrm{~m} / \mathrm{s}$ at different sections of the channel.

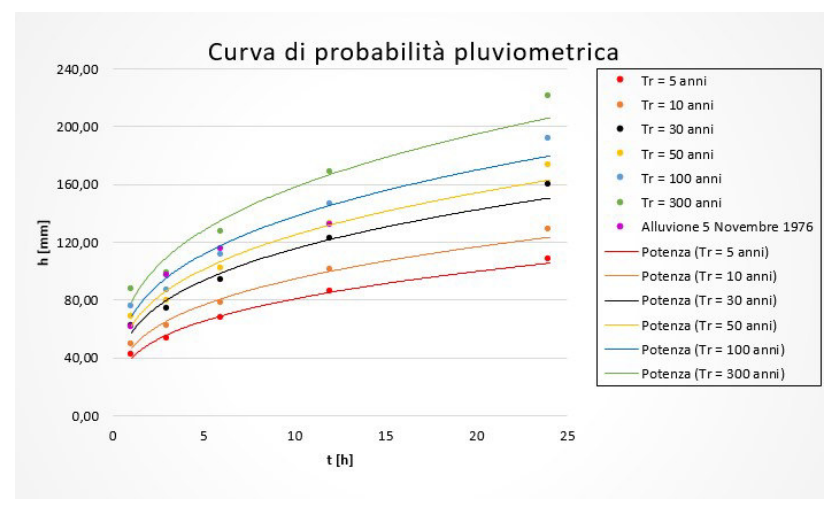

Figure 11. Pluviometric probability curves referring to return periods of $5,10,30,50,100$ and 300 years.
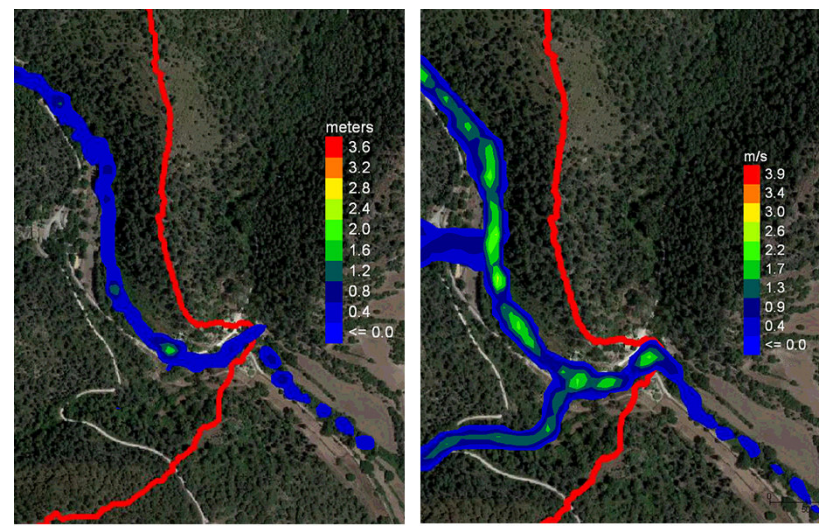

Figure 12. On the left, maximum height of the flow near the entrance to the hypogeum of Calaforno. On the right, maximum flow velocities along the watercourse near the entrance to the hypogeum of Calaforno.

\subsection{Hydraulic risk for the hypogeum}

The numerical simulation described above highlighted that the presence of an outflow barrier raises the channel water level and, considering a return time of 300 years, the water does indeed breach the hypogeum entrance, as shown in Figure 13.

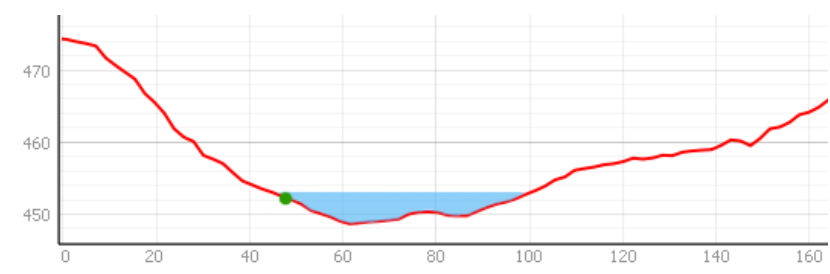

Figure 13. Terrain section at the entrance of the hypogeum (green point). Units: meters.

A real flooding risk to the archaeological site is therefore present, and could certainly compromise the preservation of hypogeum. Moreover, preliminary archaeological investigations have highlighted some doubt on the function of blocks inside the Calaforno hypogeum, and it remained unclear whether their presence is due to human activities or natural events. Analysis 
was therefore performed in order to determine whether past flood events would have been able to transport these blocks into the hypogeum.

Block movement occurs when acting instantaneous water force is larger than instantaneous resisting force related to the submerged block inertia and the friction coefficient. Digital 3D modelling was applied to reproduce calcarenite blocks with varying dimensions and volumes between $0.3 \mathrm{~m}^{3}$ and $0.02 \mathrm{~m}^{3}$, weighting between $750 \mathrm{~kg}$ and $60 \mathrm{~kg}$, respectively.

Comparing block resistance with hydraulic energy during a critical flood critical event, it does not seem likely that the blocks were transported into hypogeum by floodwater. Indeed, even if a flow velocity of about $0.5 \mathrm{~m} / \mathrm{s}$ would be sufficient to move the smaller blocks, the largest blocks would not be shifted with a flow velocity below $25 \mathrm{~m} / \mathrm{s}$, which is well above the maximum $3.5 \mathrm{~m} / \mathrm{s}$ flow velocity estimated through numerical simulation.

While the hydraulic analysis revealed significant flooding risks around the area, it is important to note that both numerical simulation and analytical analysis are subject to uncertainty resulting from different types of errors at different stages, such as the input rainfall data and geomorphological data taken from very recent periods.

In order to develop a comprehensive overview of the hydrological and hydraulic phenomena for the purpose of safeguarding the area, a 3D numerical simulation is being developed using the Flow-3D computational fluid dynamics software. These analyses are expected to derive telling information regarding the infiltration and flooding dynamics inside the hypogeum.

\section{Pennisi, M. Sanfilippo}

\section{CONCLUSION AND FUTURE RESEARCH}

This research highlights the importance of an interdisciplinary approach that combines detailed knowledge of the archaeological monument and the application of digital technologies for 3D surveying and modelling morphologically complex sites in order to effectively monitor cultural heritage for preventive assessment and risk management. Numerical modelling of the propagation phenomena of high intensity precipitation events was carried out in order to evaluate the hydraulic risks that threaten this highly significant archaeological asset, with the results establishing real flood risks in the area. Simulations carried out considering a 300years return period flood event could actually induce the flooding of the site.

Furthermore, in order to evaluate transport of large blocks by floods inside the hypogeum, the hydraulic analyses were integrated with 3D model data, obtained by the digital survey. Results indicate that it is unlikely that larger blocks were displaced at their present location within the rooms of the hypogeum during a flood event. However, it should be mentioned that while analyses reported here are based on present climatic data and recent land use, the hydrological and hydraulic conditions of the catchment area may have been very different during its history, both in terms of climatic conditions and of vegetation cover. Thus, future studies could consider different scenario simulations based on archeological and historical knowledge of site development.

\section{R. E. Musumeci}

\section{ACKNOWLEDGEMENTS}

The research was partly funded by the project PON ARS01_00926 eWAS - An Early Warning System for Cultural Heritage - PNR 2015-2020. The scientific director is Prof. Vincenzo Sapienza (Department of Civil Engineering and Architecture, University of Catania), and the responsible for on- site research activities is Prof. Pietro Militello (Department of Human Sciences, University of Catania).

Excavation activities were conducted under Project Mneme, Costruzione del passato e pratiche della memoria nel Mediterraneo, Bando Prometeo Linea 3, University of Catania. The 2017-19 and 2020 survey with the Leica P30 laser scanner was performed with the technical contribution of Antonio and Salvatore Garro (3D Dimension Company, Catania, Italy). The BLK360 laser scanner used for the 2021 survey is a equipment of the Laboratory of Architectural Photogrammetry and Surveying "Luigi Andreozzi", section of the RDA Laboratory DICAR - University of Catania (Person in charge: Prof.ssa Mariateresa Galizia). The point cloud georeferencing was performed with the technical contribution of Nicolò di Blasi (Sales Agent of Leica Geosystem) and Rosario Caruso (Technical Advisor of Leica Geosystem).

\section{REFERENCES}

Aiello, D., Basso, A., Spena, M.T., D’Agostino, G., Montedoro, U., Galizia, M., Grasso, R., Santagati, C., 2019a: The Virtual Batcave: a project for the safeguard of a UNESCO WHL fragile ecosystem. Int. Arch. Photogramm. Remote Sens. Spatial Inf. Sci., XLII-2/W9, 17-24. doi.org/10.5194/isprs-archives-XLII-2W9-17-2019.

Aiello, D., Buscemi, F., D’Agostino, G., Galizia, M., Militello P.M., Santagati, C., 2019b. Low cost techniques for the digital survey of a minoan architecture in the archeological site of Phaistos (Crete). Int. Arch. Photogramm. Remote Sens. Spatial Inf. Sci., XLII-2-W17-31, 31-38. doi.org/10.5194/isprsarchives-XLII-2-W17-31-2019.

Alessandri, L., Baiocchi, V., Del Pizzo, S., Di Ciaccio F., Onori, M., Rolfo, M. F., Troisi, S., 2020: A flexible and swift approach for 3D image-based survey in a cave. Appl. Geomat. doi.org/10.1007/s12518-020-00309-4.

Arrighi, C., Brugioni, M., Castelli, F., Franceschini, S., Mazzanti, B., 2013: Urban micro-scale flood risk estimation with parsimonious hydraulic modelling and census data. Nat Hazards Earth Syst Sci, 13, 1375-1391. doi.org/10.5194/nhess-13-13752013.

Arrighi, C., Brugioni, M., Castelli, F., Franceschini, S., Mazzanti, B., 2018: Flood risk assessment in art cities: the exemplary case of Florence (Italy). J. Flood Risk Manag, S616-S631. doi.org/10.1111/jfr3.12226.

Bonacini, E., D'Agostino, G., Galizia, M., Santagati, C., Sgarlata, M., 2013: Hidden cultural landscapes: survey and digital enhancement of the catacombs of San Giovanni in Syracuse. In: Gambardella C. (ed), Heritage architecture landesign focus on conservation regeneration innovation. Le vie dei Mercanti_XI Forum Internazionale di Studi, Napoli, pp. 262 - 271, La Scuola di Pitagora.

Camuffo, D., Bertolin, C., Schenal, P., 2014: Climate change, sea level rise and impact on monuments in Venice. Science, Technology and Cultural Heritage - Proceedings of the 2nd International Congress on Science and Technology for the Conservation of Cultural Heritage, Sevilla, Spain.

Clini, P., Nespeca, R., Angeloni, R., and Mammoli, R., 2019: The integrated survey of narrow spaces and underground architecture: 
the case study of Campana Cave bas-reliefs, Int. Arch. Photogramm. Remote Sens. Spatial Inf. Sci., XLII-2/W9, 277282. doi.org/10.5194/isprs-archives-XLII-2-W9-277-2019.

D’Agostino, G., Figuera, M., Rodonò, G., 2021: Digital survey and reception structures for a virtual fruition: the case study of the hypogeum of Calaforno (Ragusa), ARQUEOLÓGICA 2.0 9th International Congress \& 3rd GEORES - GEOmatics and pREServation, Valencia, 569-572.

Dassanayake, D.R., Burzel, A., Oumeraci, H., 2012: Evaluation of cultural losses, Xtrem RisK Progress Report. LeichtweißInstitute for Hydraulic Engineering and Water Resources, Technische Universität Braunschweig, 1-44.

Ebolese, D., Lo Brutto, M., Dardanelli, G., 2019: The integrated 3D survey for underground archeological environment. Int. Arch. Photogramm. Remote Sens. Spatial Inf. Sci., XLII-2/W9, 311317. doi.org/10.5194/isprs-archives-XLII-2-W9-311-2019.

European Parliament, 2007: Protecting the cultural heritage from natural disaster.

https:/www.europarl.europa.eu/RegData/etudes/etudes/join/200 7/369029/IPOL-CULT_ET(2007)369029_EN.pdf(05/07/2021)

Figuera, M., 2018. Patrimonio diffuso, comunità locali. La "riscoperta": per una ipotesi di valorizzazione innovativa dell'ipogeo di Calaforno. Archivio Storico per la Sicilia Orientale, 2018(1), 5-23. doi.org/10.3280/ASSO2018-001001.

Gallay, M., Kaňuk, J., Hochmuth, Z., Meneely, J. D., Hofierka, J., Sedlák, V., 2015. Large-scale and high-resolution 3-D cave mapping by terrestrial laser scanning: a case study of the Domica Cave, Slovakia, International Journal of Speleology, 44: 277291. doi.org/10.5038/1827-806X.44.3.6.

Guzzardi, L. 1980. Un ipogeo preistorico a Calaforno e il suo contesto topografico. Sicilia Archeologica, 42, 67-94.

Lanza S.G., 2003: Flood hazard threat on cultural heritage in the town of Genova (Italy). $J$ Cult Herit, 4, 159-167. doi.org/10.1016/S1296-2074(03)00042-6.

Militello, P.M., 2021: Calaforno I. Le indagini 2013-2017. Archaeopress, Oxford.

Militello, P.M., Di Stefano, G. 2015: Calaforno (Giarratana, Prov. di Ragusa). Indagini 2013-2014. Notiziario di Preistoria e Protostoria 2(II), 63-65.

Militello, P.M., Sammito, A.M., Scerra, S., 2018: Calaforno (Giarratana, RG). Notiziario di Preistoria e Protostoria 5(II), 9093.

Murthy, M., 2013: Heritage and resilience. Issues and opportunities fo reducing disaster risks. UNISDR.

https://www.researchgate.net/publication/327906144_HERITA GE_AND_RESILIENCE_Issues_and_Opportunities_for_Redu cing_Disaster_Risks

Musumeci, R.E., Foti, E., Li Rosi, D., Sanfilippo, M., Stancanelli, L.M., Sapienza, V., Yang, W., Patanè, D., 2021: Debris flow hazard assessment at the archaeological UNESCO World Heritage site 1 of Villa Romana del Casale (Sicily, Italy). International Journal of Disaster Risk Reduction (under revision).
Nicu, I.C., 2019: Natural Hazards vs Cultural Heritage. Encyclopedia of Global Archaeology, Springer, New York, 1-12. doi.org/10.1007/978-3-030-30018-0_3185.

O'Callaghan, J.F., Mark, D.M., 1984: The extraction of drainage networks from digital elevation data. Computer Vision, Graphics and Image Processing, 28:323-344. doi.org/10.1016/S0734189X(84)80011-0.

Perfetti, L., Polari, C., Fassi, F., Troisi, S., Baiocchi, V., Del Pizzo S., Giannone, F., Barazzetti, L., Previtali, M., Roncoroni, F., 2018: Fisheye Photogrammetry to Survey Narrow Spaces in Architecture and a Hypogea Environment. In Latest Developments in Reality-Based 3D Surveying and Modelling; Remondino, F., Georgopoulos, A., González-Aguilera, D., Agrafiotis, P., Eds.; MDPI: Basel, Switzerland pp. 3-28. DOI: 10.3390/books978-3-03842-685-1-1.

Pukanská, K., Bartoš, K., Bella, P., Gašinec, J., Blistan, P., Kovanič, L., 2020: Surveying and High-Resolution Topography of the Ochtiná Aragonite Cave Based on TLS and Digital Photogrammetry. Appl. Sci., 10(13), 4633. doi.org/10.3390/app10134633.

Rodríguez-Gonzálvez, P., Nocerino, E., Menna, F., Minto, S., and Remondino, F., 2015: 3D surveying \& modeling of underground passages in WWI fortifications, Int. Arch. Photogramm. Remote Sens. Spatial Inf. Sci., XL-5/W4, 17-24. doi.org/10.5194/isprsarchives-XL-5-W4-17-2015.

Santagati, C., 2014: Metodologie digitali per il rilievo e la valorizzazione del patrimonio culturale ipogeo. Virtual Archeology Review, 5:82-92. ISSN: 1989-9947. doi.org/10.4995/var.2014.4222.

Saulli, T., Wahbeh, W., Nardinocchi, C., 2018: 3D survey and digital models as the first documentation of hypogeum of S. Saba in Rome. Appl. Geomat., Vol. 10, Issue 4, pp. 377-384. doi.org/10.1007/s12518-018-0244-0.

Tanasi, D., Hassam, S., Kingsland, K., 2021: Underground Archeology: Photogrammetry and Terrestrial Laser Scanning of the Hypogeum of Crispia Salvia (Marsala, Italy). Pattern Recognition. ICPR International Workshops and Challenges, pp. 353-367. doi.org/10.1007/978-3-030-68787-8_27.

UNESCO, 2010: Managing disaster risks for world heritage, World Heritage Resource Manuals Series. https://whc.unesco.org/en/documents/115730. (05/07/2021) 